\title{
Italian adaptation of the brief modified experiences in close relationships scale in a sample of cancer patients: factor analysis and clinical implications
}

\author{
Davide Ghirardello, ${ }^{1}$ Jacopo Munari, ${ }^{2}$ Silvia Testa, ${ }^{1}$ Riccardo Torta, ${ }^{3}$ Fabio Veglia, ${ }^{1}$ Cristina Civilotti ${ }^{1,4}$ \\ ${ }^{1}$ Department of Psychology, University of Turin; ${ }^{2}$ Clinical and Oncological Psychology Unit, Città della Salute Hospital; ${ }^{3 *}$ Rita Levi \\ Montalcini” Department of Neuroscience, University of Turin; ${ }^{4}$ Salesian University Institute Torino Rebaudengo (IUSTO), Turin, Italy
}

\begin{abstract}
Many previous studies have indicated that the attachment pattern developed during infancy shapes the adult attachment style, which in turn affects responses to stress and help-seeking behaviors. It may be relevant within clinical contexts to have easy-to-administer and rapid tools aimed to investigate attachment dimensions. The current study presents the Italian adaptation of the Brief Modified Experiences in Close Relationships (ECR-M16) - a self-reported measure of the attachment-style dimensions with reference to close others and assesses its factorial structure. The questionnaire was administered to cancer outpatients. The number of factors to be extracted was calculated via parallel analysis. Subsequently, an exploratory factor analysis was run to calculate the first-order factor structure, which was compared to the original one via Procrustes rotation and Tucker's coefficient. Finally, a second-order factor structure was calculated by factor analyzing the first-order factor scores. The Italian adaptation of the ECR-M16 is characterized by a first-order factor structure comprising four factors, like the original. The de-

Correspondence: Jacopo Munari, Clinical and Oncological Psychology Unit, Città della Salute Hospital, Corso Bramante 88-90, 10126 Turin, Italy.

Tel: +39.011.6334200.

E-mail: jmunari@cittadellasalute.to.it

Citation: Ghirardello, D., Munari, J., Testa, S., Torta, R., Veglia, F., \& Civilotti, C. (2018). Italian adaptation of the brief modified gree of similarity between the two ranges between fair and dissimilar. The second-order factor structure comprises two higher order dimensions, like in the original study. Although partially similar, the two second-order factor structures show relevant differences. A clinically oriented discussion centered on the similarities and differences between the two factor structures is provided, along with indications for future studies.
\end{abstract} experiences in close relationships scale in a sample of cancer patients: factor analysis and clinical implications. Research in Psychotherapy: Psychopathology, Process and Outcome, 21(3), 209-217. doi: 10.4081/ripppo.2018.319

Acknowledgments: the authors would like to express warm gratitude to the patients who participated in the project for their time and willingness to contribute to the study.

See online Appendix for additional materials.

Contributions: DG, manuscript writing and reviewing and reference searching and data analyses; JM, research design planning, data collection, and manuscript reviewing; ST, data analyses and manuscript reviewing; RT, FV questionnaire translation and manuscript reviewing; $\mathrm{CC}$, research design planning, reference searching, and manuscript writing and reviewing.

Conflict of interest: the authors declare no potential conflict of interest.

Funding: none.

Received for publication: 16 July 2018.

Revision received: 20 September 2018.

Accepted for publication: 4 October 2018.

This work is licensed under a Creative Commons Attribution NonCommercial 4.0 License (CC BY-NC 4.0).

C Copyright D. Ghirardello et al., 2018

Licensee PAGEPress, Italy

Research in Psychotherapy:

Psychopathology, Process and Outcome 2018; 21:209-217

doi:10.4081/ripppo.2018.319
Key words: Experiences in close relationships; Attachment; Assessment; Cancer.

\section{Introduction}

Attachment theory poses that, throughout the lifespan, stressful and threatening conditions activate the behavioral system of attachment (Bowlby, 1969/1982; Crowell, Fraley, \& Roisman, 2016), which is interiorized as and then modulated by implicit cognitive structures of memories and expectations about relationships between the self and others, called internal working models (IWM) (Bretherton \& Munholland, 2016; Kobak, Zajac, \& Madsen, 2016). An IWM overtly manifests in terms of behavioral patterns, which go under the concept of attachment styles (Fortuna \& Roisman, 2008). In short, individuals who have developed a secure IWM tend to see themselves as worth other person's help and have no problem asking for help if needed. Conversely, individuals who have developed an insecure IWM fall into two broad groups: i) anxious-resistant individuals who are characterized by a hyperactivation of the attachment system, accompanied by a difficulty to soothe the anxiety when helped by another person and ii) those who have developed an anxious-avoidant IWM who still have an activation of the attachment system, which will be minimized based on the learned unreliability of significant others in times of need (Crowell et al., 2016). 
A convenient method of assessing attachment styles in adulthood is by means of self-reports (Crowell et al., 2016). Even though originally designed within a categorical framework (Hazan \& Shaver, 1987), self-reports later turned out to better assess the underlying dimensions of attachment styles (Brennan, Clark, \& Shaver, 1998; Fortuna \& Roisman, 2008; Fraley, Hudson, Heffernan, \& Segal, 2015; Griffin \& Bartholomew, 1994; Mikulincer \& Shaver, 2016). Specifically, two major dimensions emerged concerning attachment insecurity, namely attachment anxiety and attachment avoidance (Brennan et al., 1998; Crowell et al., 2016; Mikulincer \& Shaver, 2016).

Physical illness represents one of the major examples of stressful and painful experiences that may trigger the activation of the attachment system (Bowlby, 1969/1982; Hunter \& Maunder, 2001; Mikulincer \& Shaver, 2016). Although the literature concerning the implications of attachment theory with respect to physical illness is quite vast, we focus on contributions that have highlighted the importance of patients' interiorized attachment style with respect to illness development, subsequent adjustment, and healthcare compliance. We can trace a path that stems from an initial call to explore the mechanisms that link social relationships to health, along with the processes and factors that lead to developing and maintaining social relationships (House, Landis, \& Umberson, 1988). In this regard, attachment theory gave rise to a huge amount of research concerning the development of close and social bonds, making it a pivotal theory to address the importance of close and social relationships in relation to illness and health (Pietromonaco, Uchino, \& Schetter, 2013).

Numerous researchers have investigated the implications of attachment styles for illness and health patterns and behaviors from childhood to adulthood (Feeney, 2000; Feeney \& Ryan, 1994; McWilliams \& Bailey, 2010; Scharfe \& Eldredge, 2001). Hunter and Maunder (2001) proposed a theoretical framework to consider illness behavior in adulthood in light of the attachment styles, particularly highlighting the facets associated with insecure styles. The same authors (Maunder \& Hunter, 2001) also developed a preliminary hypothetical causal model, linking attachment insecurity to illness via three mechanisms: increased stress susceptibility, increased regulation of affect through external regulators, and altered help and careseeking behavior. Until now, several studies seem to speak in favor of this model. For example, attachment insecurity has been linked to poor treatment adherence in patients with diabetes (Ciechanovski, Katon, Russo, \& Walker, 2001). In addition, more securely attached individuals have been shown to better adjust to HIV/AIDS (TurnerCobb et al., 2002). The compliance to screening analysis in women with breast cancer has been found to be negatively affected by attachment insecurity, although attachment explained only a small portion of the total variance (Tuck \& Consedine, 2015).

Recent work has also highlighted the importance of evaluating the above-mentioned attachment-style dimensions in people suffering for physical illness (specifically cancer) to better tailor supportive and clinical interventions (Holwerda et al., 2013; Nicholls, Hulbert-Williams, $\&$ Bramwell, 2014). It seems in fact that these dimensions predict different trajectories of psychological adjustment to cancer, especially in terms of perceived social support (Cicero, Lo Coco, Gullo, \& Lo Verso, 2009), adopted coping strategies (Schmidt, Blank, Bellizzi, \& Park, 2012; Schmidt, Nachtigall, Wuethrich-Martone, \& Strauss, 2002;), and trust and satisfaction in the relationship between patients and healthcare providers, such as physicians (Hinnen et al., 2014; Holwerda et al., 2013), nurses (Harding, Beesley, Holcombe, Fisher, \& Salmon, 2015; Hawkins, Howard, \& Oyebode, 2007) and social workers (Lo et al., 2014).

Considering the lack of a brief self-report to assess attachment dimensions in physically ill patients in a medical context, where attachment figures are not limited to romantic partners, Lo et al. (2009) modified the Experiences in Close Relationships (ECR) (Brennan et al., 1998). While the ECR was originally developed to assess the attachment-style dimensions with reference to romantic partners, the items of the modified version (called Modified ECR, ECR-M36) have been changed to include a broader range of close others (including, but not limiting to, partners). The new questionnaire was administered to a sample of cancer patients. Lo et al. (2009) eventually proposed a brief, 16-item version of the ECR-M36. Different from the original ECR (Brennan et al., 1998), the Brief Modified Experiences in Close Relationships (ECRM16) showed a two-order hierarchical structure with four first-order factors contributing to the two traditional dimensions of anxiety and avoidance (Brennan et al., 1998; Crowell et al., 2016). A recent adaptation of the ECR-M16 to the German context confirmed, with slight differences, this hierarchical structure (Phillipp et al., 2017), while the adaptation to the Greek context showed a non-hierarchical, three-factor structure (Tsilika et al., 2016).

To our knowledge, the Italian context lacks a self-report tool like the ECR-M16 (Lo et al., 2009), which is quick to administer, and specifically designed to include a broader range of attachment figures, perhaps encompassing healthcare providers (Maunder \& Hunter, 2016). The aim of the present study was thus to propose the Italian adaptation of the ECR-M16 and to assess its factorial structure. The general hypothesis was that the two-order factor structure found by Lo et al. (2009) would have been replicated in the Italian context. More specifically, we expected to find four first-order factors with the same item composition found by Lo et al. (2009) and that the loadings of the first-order factors onto the two second-order dimensions of anxiety and avoidance would have been comparable to those emerged in the original study. Considering that the ECR-M16 was designed to suit the conditions of a medical setting, for the sake of coherence with 
the original study, we administered the questionnaire to a cancer patient sample.

\section{Materials and Methods}

\section{Translation of the modified experiences in close relationships}

The ECR-M36 (Lo et al., 2009) was translated into Italian following the procedure called forward translation. Two authors, FV and RT, translated the questionnaire; both speak mother-tongue Italian with great English language knowledge. An expert in the field of attachment theory and a psychotherapist, FV translated the ECR-M36 with reference to the Italian ECR for romantic partners (Picardi et al., 2002). In contrast, RT, who is an internationally distinguished expert in the field of psycho-oncology, translated the ECR-M36 without considering the Italian ECR. The Italian version was named ECR-M36-I and was administered to the participants following the procedure discussed in the next paragraph. As for the original version, participants indicated their degree of agreement with the statements of the items using a 7-point Likert scale ( $1=$ completely false; $7=$ completely true $)$. Cronbach's alpha was used as a measure of internal consistency. As for the classic ECR (Brennan et al., 1998), two 18-item subscales were considered: avoidance (uneven items) and anxiety (even items). Internal consistency for these scales was quite high, with a Cronbach's alpha of .84 and .89 , respectively.

\section{Procedure and participants}

The research took place at the Centro Oncologico ed Ematologico Subalpino (Subalpine Oncology and Hematology Center) of the Azienda Sanitaria Ospedaliera San Giovanni Battista of Turin. Participation was voluntary and based on written informed consent. Confidentiality, anonymity, and respect for ethical aspects were assured in accordance with the Declaration of Helsinki (World Medical Association, 2013) and upon the approval of the ethic panel of the Azienda Sanitaria Ospedaliera San Giovanni Battista of Turin.

Participants eligible for the present study were outpatients who were 18 years of age or older currently in treatment with chemotherapy and/or radiotherapy and diagnosed with a Stage I-III solid tumor (gastrointestinal, genitourinary, or lung cancer). Patients indicated by the hospital staff as presenting psychiatric comorbidity were excluded from the study as well as those having difficulties in understanding the Italian language. Overall, 132 patients took part in the study by completing the ECR-M36-I, along with a sociodemographic questionnaire. Eventually, 86 participants provided complete ECR data. They had mean age of 56.3 years $(\min .=29$, $\max .=78, \mathrm{SD}=11.4)$. There were 53 men (61.6\%) and 33 women (38.4\%).

The analyses discussed in the paper focused on the 86 complete ECR-M36-I questionnaires and were performed on the short version (ECR-M16-I), composed by the same 16 items selected by Lo et al. (2009). For the sake of comparison with the extended versions of the ECR, the items of the ECR-M16-I are numbered according to the full ECR-M36.

\section{Statistical analyses}

Statistical analyses were carried out with IBM SPSS Statistics (v. 24), and R (v. 3.2.2). Given the small sample size, a confirmatory factor analysis (CFA) was not suitable to test the original hierarchical factor structure (Lo et al., 2009) on our data, so an exploratory approach was followed to extract the factor structure of the ECR-M16I and then compare it to the original one. The first step consisted of the estimation of the number of factors to be extracted. As indicated by several authors (Fabrigar, Wegener, MacCallum, \& Strahan, 1999; O'Connor, 2000), the rules of thumb that are typically endorsed to extract the number of factors for an exploratory factor analysis (EFA) or a principal component analysis (namely, an eigenvalue greater than 1 and a scree plot examination), could be problematic. To solve the problem, we performed a parallel analysis, a method to calculate the number of factors to be retained with wide support in the methodological literature (Fabrigar et al., 1999; O'Connor, 2000). Subsequently, an EFA was run with principal axis factoring (PAF) to obtain the first-level factor structure. Both oblimin $($ delta $=0)$ and promax $(K=4)$ rotations were used, allowing the first-order factors to correlate. The two rotations yielded almost identical factor compositions. The promax rotation was retained for the sake of comparability with the original study (Lo et al., 2009). The third step consisted in the comparison between our first-order factor structure and the original one (Lo et al., 2009), which was pursue by running the Procrustes rotation package in R, and assessed using Tucker's congruence coefficient, a widely used index of factor similarity (Lorenzo-Seva \& ten Berge, 2006). The fourth and final step consisted in the calculation of the second-order factor structure. To this aim, while running the promax-rotated EFA, the first-order factor scores were calculated using the regression method. These factor scores were then factor analyzed, specifying the extraction of two secondorder factors (i.e., avoidance and anxiety). An EFA with $\mathrm{PAF}$ was performed, with a promax rotation to quantify the correlation between the two second-order factors. First- and second-order loadings greater than .40 were judged as substantially high (Floyd \& Widaman, 1995).

\section{Results}

\section{Parallel analysis and number of factors retained}

The parallel analysis was performed by running the PAF extraction method and comparing the empirical eigenvalues with eigenvalues corresponding to the $95^{\text {th }}$ percentile 
of the distribution based on random data: factors must be retained as long as the empirical eigenvalue is greater than the corresponding simulated value. From the fifth factor onwards, the raw data eigenvalues were smaller than the random data ones. The first, second, and fourth factors matched the criterion, while the third factor did not. For the sake of being cautious about the simplification we introduce (Fabrigar et al., 1999), we chose to retain four factors, with the fourth factor having an eigenvalue of $0.70 \mathrm{com}-$ pared to 0.66 of the $95^{\text {th }}$ percentile (based on both raw data permutation and random normal data generation).

\section{First-order factor structure: description and congruence evaluation}

The promax-rotated first-order solution is shown in Table 1 . The first factor comprises six items, namely 2,4 , 6 , and 8 (the four items composing the original factor worrying about relationships), plus Items 7 and 26. Let's look closely at the content of these last two items (Appendix), which loaded on two different factors in the original version. Item 7 refers to the subject as passively feeling uncomfortable when other people want to be very close to the subject; thus, it could be possible that this item taps a dimension of worry about what others will do. Similarly, Item 26 refers directly to desired closeness, a desire that is believed to be unreciprocated by the close others. Overall, these six items seem to tap a wider dimension of worries about loss, abandonment, caring and closeness (WLACC), and we renamed the factor accordingly. The second factor comprises Items 18,30 , and 36 , plus a smaller loading of Item 26, which is in the codomain with the WLACC factor. For completeness, the second factor was renamed frustration about unavailability and need for reassurance (FUNR), instead of simply frustration about unavailability. The third factor clearly comprises Items 25 and 31, while Items 27 and 33, as expected, showed a higher positive loading on this factor and a non-negligible negative loading on the FUNR factor. To be conservative with respect to the original factor structure, Item 33 was considered to belong to this factor, although its loading falls below the .40 threshold. Nonetheless, to better adhere to the item content, the factor was renamed difficulty in relying upon others (DRO) instead of turning away from others. Finally, the fourth factor comprises Items 23,17 , and 9, which reflect the subject as being active with respect to closeness. Although Item 17 shows a small loading on the FUNR factor, its loading on this factor is clearly higher. In contrast, Item 9 also loads on the $W L A C C$ factor, and the difference between the two loadings (.31 vs .47) is small, so it should be considered in the codomain. As in the original version, we named this factor discomfort with closeness (DC). Overall, the four factors explained $50.4 \%$ of the total variance.

Tucker's congruence coefficients following the application of the Procrustes rotation are shown in Table 2. With the Procrustes rotation, the factors of the investigated matrix are rotated to fit with a target matrix
(Lorenzo-Seva \& ten Berge, 2006). In this case, the target matrix was represented by the factor loadings reported in the original paper (Lo et al., 2009, p. 496) (Figure 1). A Tucker's coefficient in the range of .85-.94 means that two factors have a fair similarity (Lorenzo-Seva \& ten Berge, 2006), and values below .85 should not be interpreted as indicative of some sort of similarity. Considering the preliminary nature of our study, the degree of similarity between 2 out of the 4 paired factors can be considered almost fair (.84). Our $D C$ factor is fairly similar to the original one (.88). Finally, the similarity between WLACC and the original worrying about relationships factor is, as foreseeable, scarce (.79).

\section{Second-order factor structure}

The second-order factor structure is shown in Figure 1. The promax rotation evidenced a correlation of .41 between the two second-order factors, named avoidance and anxiety, which should not be discarded as negligible. By looking at the diagram, it clearly appears that two first-order factors load specifically onto only one second-order dimension, namely DRO on avoidance (.87) and FUNR on anxiety (.83). The other two first-order factors load on both secondorder dimensions. Specifically, WLACC is in the codomain (.40 on avoidance and .61 on anxiety), while $D C$ is more strongly related to avoidance (.68) than anxiety (.16).

\section{Discussion}

In this paper, the first Italian version of the ECR-M16 (Lo et al., 2009) is presented (Appendix). The analysis of its factor structure allows us to pinpoint some interesting clinical aspects that will foster future studies on the ECR. As we saw in the results section, the first-order factor structure is in part similar and in part different with respect to

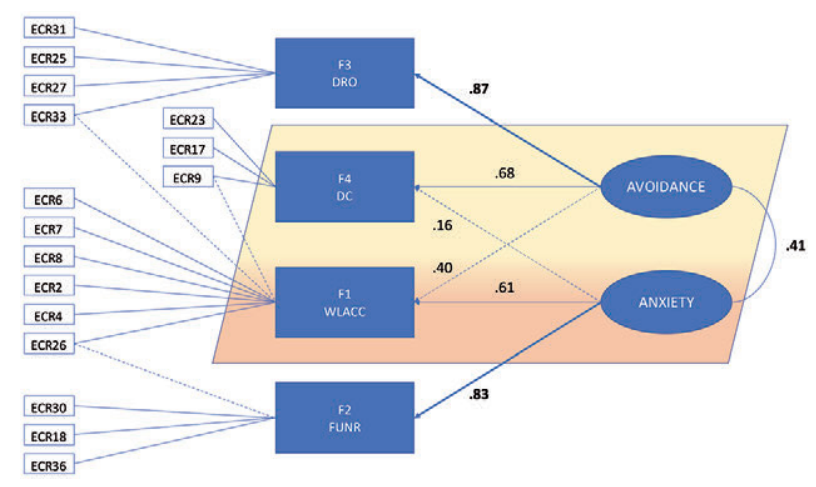

Figure 1. First-order and second-order factor structure of the ECR-M16-I. The dashed lines identify secondary loadings (see text for details). DRO, difficulty in relying upon others; DC, discomfort with closeness; WLACC, worries about loss, abandonment, caring and closeness; FUNR, frustration about unavailability and need for reassurance. 
the original version. The most puzzling result was observed by comparing our WLACC factor to the original worrying about relationships, with which it shares Items 2, 4, 6, and 8 . Here, the most unexpected result is the presence of Item 7 (traditionally related to the avoidance dimension) in a fac- tor of even items (traditionally related to the anxiety dimension; Brennan et al., 1998; Lo et al., 2009).

The remaining three factors more closely resemble the original ones, as shown by Tucker's coefficient. Nonetheless, several differences emerged. The FUNR factor shows

Table 1. ECR-M16-I first-order factor loadings resulting from the promax-rotated exploratory factor analysis.

\begin{tabular}{|c|c|c|c|c|}
\hline \multirow[t]{2}{*}{ ITEMS } & \multicolumn{4}{|c|}{ MODEL MATRIX - FACTORS } \\
\hline & WLACC & FUNR & DRO & DC \\
\hline $\begin{array}{l}\text { ECR6 } \\
\text { I worry that other people won't care about me as much as I care about them } \\
\text { Temo che gli altri non tengano a me quanto io tengo a loro }\end{array}$ & .69 & .04 & .04 & .03 \\
\hline $\begin{array}{l}\text { ECR } 7 \\
\text { I get uncomfortable when other people want to be very close to me } \\
\text { Mi sento a disagio quando gli altri vogliono avvicinarsi a me }\end{array}$ & .65 & .02 & .07 & .15 \\
\hline $\begin{array}{l}\text { ECR8 } \\
\text { I worry a fair amount about losing people with whom I feel close } \\
\text { Mi preoccupo molto di perdere le persone che sento vicine }\end{array}$ & .62 & .13 & -.18 & -.05 \\
\hline $\begin{array}{l}\text { ECR2 } \\
\text { I worry about being abandoned } \\
\text { Ho paura di essere abbandonata/o }\end{array}$ & .59 & .16 & .14 & -.05 \\
\hline $\begin{array}{l}\text { ECR4 } \\
\text { I worry a lot about my relationships } \\
\text { Mi preoccupo molto per le mie relazioni con gli altri }\end{array}$ & .45 & -.01 & -.22 & -.20 \\
\hline $\begin{array}{l}\text { ECR26 } \\
\text { I find that other people don't want to get as close as I would like } \\
\text { Trovo che gli altri non vogliano stabilire con me quella vicinanza che desidererei raggiungere }\end{array}$ & .42 & .31 & -.01 & .07 \\
\hline $\begin{array}{l}\text { ECR30 } \\
\text { I get frustrated when other people are not around as much as I would like } \\
\text { Mi sento frustrata/o quando gli altri non sono presenti quanto io vorrei }\end{array}$ & .09 & .74 & -.03 & -.07 \\
\hline $\begin{array}{l}\text { ECR18 } \\
\text { I need a lot of reassurance that I am loved by people with whom I feel close } \\
\text { Ho bisogno di molte rassicurazioni sul fatto di essere amata/o dalle persone che sento vicine }\end{array}$ & .06 & .64 & .05 & .06 \\
\hline $\begin{array}{l}\text { ECR36 } \\
\text { I resent it when other people with whom I feel close spend time away from me } \\
\text { Me la prendo quando le persone che sento vicine passano del tempo lontano da me }\end{array}$ & .18 & .56 & -.06 & -.01 \\
\hline $\begin{array}{l}\text { ECR33 (reversed score) } \\
\text { It helps to turn to other people in times of need } \\
\text { Mi è di aiuto rivolgermi agli altri nei momenti di bisogno }\end{array}$ & .26 & -.35 & .29 & .15 \\
\hline $\begin{array}{l}\text { ECR31 (reversed score) } \\
\text { I don't mind asking other people for comfort, advice, or help } \\
\text { Non mi crea problemi chiedere conforto, consiglio o aiuto agli altri }\end{array}$ & -.03 & .18 & .99 & -.18 \\
\hline $\begin{array}{l}\text { ECR25 (reversed score) } \\
\text { I tell people with whom I feel close just about everything } \\
\text { Alle persone che sento vicine dico quasi tutto }\end{array}$ & -.12 & -.04 & .67 & .03 \\
\hline $\begin{array}{l}\text { ECR27 (reversed score) } \\
\text { I usually discuss my problems and concerns with people with whom I feel close } \\
\text { Di solito parlo con le persone che sento vicine dei miei problemi e delle mie preoccupazioni }\end{array}$ & -.04 & -.35 & .49 & -.02 \\
\hline $\begin{array}{l}\text { ECR23 } \\
\text { I prefer not to be too close to other people } \\
\text { Preferisco non avvicinarmi troppo alle altre persone }\end{array}$ & -.04 & -.13 & -.19 & .88 \\
\hline $\begin{array}{l}\text { ECR17 } \\
\text { I try to avoid getting to close to other people } \\
\text { Cerco di evitare di raggiungere una eccessiva vicinanza con le altre persone }\end{array}$ & -.18 & .32 & .10 & .85 \\
\hline $\begin{array}{l}\text { ECR9 } \\
\text { I don't feel comfortable opening up to other people } \\
\text { Ho difficoltà ad aprirmi con gli altri }\end{array}$ & .31 & -.14 & .12 & .47 \\
\hline
\end{tabular}

Extraction method: PAF. Rotation method: Promax with Kaiser normalization. Convergence obtained after 6 iterations. Factor loadings $>.40$ are in boldface. WLACC, worries about loss, abandonment, caring and closeness; FUNR, frustration about unavailability and need for reassurance; DRO, difficulty in relying upon others; DC, discomfort with closeness. 
smaller loadings of Item 26. In addition, $D R O$, which is identical to the original one in terms of item composition, shows a lower loading of Item 33 (0.29 vs 0.86) and a higher loading of Item 25 (0.67 vs 0.27). Finally, the factor $D C$ is more congruent to the original one, although Item 7 is not included and Item 9 is in the codomain with the $W L A C C$ factor.

The second-order factor structure is also partially similar and partially different compared to the published hierarchical factor structures of the ECR-M16 (Lo et al., 2009; Phillipp et al., 2017). The loadings of the factors $W L A C C$ and $D C$ onto both second-order dimensions avoidance and anxiety represent the differences with respect to the original factor structure, where a unique factor (namely, discomfort with closeness) contributed to both avoidance and anxiety. The similarities concern the remaining two first-order factors: FUNR loads exclusively on anxiety, while DRO loads exclusively on avoidance. The specificity of each of these two factors with respect to a single second-order dimension seems to be constant across different countries (Lo et al., 2009; Phillipp et al., 2017), although the second-order structure in the Greek sample did not emerge (Tsilika et al., 2016). Moreover, the correlation of 41 between avoidance and anxiety is in line with the extant literature (Crowell et al., 2016; Brennan et al., 1998; Lo et al., 2009; Phillipp et al., 2017).

Therefore, and contrary to our hypotheses, the factor structure of the ECR-M16-I discussed herein shows nonnegligible differences compared to the original ECR-M16 (Lo et al., 2009). Moreover, although the German version of the ECR-M16 was largely similar to the original one (Phillipp et al., 2017), the Greek adaptation of the ECRM16 showed a non-hierarchical, three-factor structure (Tsilika et al., 2016). On the whole, these factor structures differ remarkably from the classic ECR (Brennan et al., 1998).

These considerations elicit questions of clinical relevance. How many different underlying factors constitute the factor structure of the modified versions of the ECR?
What kind of psychological dimensions are tapped by this questionnaire? The second-order structure characterizing the ECR-M16 shows that the two main dimensions avoidance and anxiety do not seem to be clearly independent, and this casts a shadow on how to interpret the results of the ECR, at least in this modified version administered to cancer samples. For example, it does not seem to be psychometrically correct to simply summarize the even and uneven items to obtain two scores of anxiety and avoidance since several items compose first-order factors that contribute to both the second-order dimensions.

Despite these relevant questions, the extant research on the ECR-M16 (Lo et al., 2009; Phillipp et al., 2017), along with the present study, allow us to draw an indication of clinical interest. According to a widely known model of adult attachment (Crowell et al., 2016; Shaver $\&$ Mikulincer, 2002), the activation of the attachment system includes three major components: the first entails monitoring the environment for threatening, distress-eliciting events. The second component involves monitoring for the psychological proximity of the attachment figure (anxiety dimension). The third, which is activated in response to the second, entails the regulation of attachment behaviors, such as asking for help or seeking contact (avoidance dimension). Even though for now we are not defining the subscales of the ECR-M16-I, it could make sense that the scoring on the items of the FUNR factor (specifically loading on the anxiety dimension) taps the second component, while the scoring on the items of the $D R O$ factor (specifically loading on the avoidance dimension) taps the third one. The possibility to discriminate between attachment anxiety and avoidance with respect to adjustment and coping with illness, including the sense of trust toward the clinician, has been receiving growing attention in the literature investigating the relationships among attachment-style dimensions, cancer illness, and the various facets connected to health care.

As per the psychological and psychopathological dimen-

Table 2. Comparison between the Procrustes-rotated ECR-M16-I first-order factor structure and the original one, assessed with Tucker's coefficients.

\begin{tabular}{|c|c|c|c|c|}
\hline \multirow[b]{2}{*}{$\begin{array}{l}\text { Procrustes-rotated } \\
\text { ECR-M16-I } \downarrow\end{array}$} & \multicolumn{4}{|c|}{ Lo et al.’s (2009) factors } \\
\hline & $\begin{array}{c}\text { F4 } \\
\text { Worrying about } \\
\text { relationships }\end{array}$ & $\begin{array}{c}\text { F1 } \\
\begin{array}{c}\text { Frustration about } \\
\text { unavailability }\end{array}\end{array}$ & $\begin{array}{c}\text { F3 } \\
\text { Turning away } \\
\text { from others }\end{array}$ & $\begin{array}{c}\text { F2 } \\
\text { Discomfort } \\
\text { with closeness }\end{array}$ \\
\hline $\begin{array}{l}\text { F1 } \\
\text { WLACC }\end{array}$ & .79 & .17 & .02 & .18 \\
\hline $\begin{array}{l}\text { F2 } \\
\text { FUNR }\end{array}$ & .18 & .84 & -.11 & .05 \\
\hline $\begin{array}{l}\text { F3 } \\
\text { DRO }\end{array}$ & .02 & -.11 & .84 & .08 \\
\hline $\begin{array}{l}\text { F4 } \\
\text { DC }\end{array}$ & .13 & .05 & .07 & .88 \\
\hline
\end{tabular}

WLACC, worries about loss, abandonment, caring and closeness; FUNR, frustration about unavailability and need for reassurance; DRO, difficulty in relying upon others; DC, discomfort with closeness. 
sions of adjustment to cancer, the systematic review of the literature provided by Nicholls et al. (2014) showed different results across studies. In some, an anxious attachment style was consistently associated with depression, higher anxiety, and lower levels of social well-being, while an avoidant attachment style was associated with higher levels of depression and trait anxiety, poor marital quality, and poor perceived quality of life. The authors then highlighted that the differences between the two insecure styles clearly emerged at the level of reaction to disease burden, as shown in a different study. Individuals scoring higher on the anxiety dimension showed increased depression in reaction to disease burden, while those scoring higher on attachment avoidance were characterized by downplaying their emotional difficulties, as indicated by the lower score for depression associated with attachment avoidance, regardless of disease burden. Nissen's systematic review and meta-analysis (Nissen, 2016) showed that avoidant and anxious attachment were both associated with depressive symptoms with a small effect size. However, anxious attachment was positively associated with anxiety and negatively associated with social support, meeting the criterion for a moderate effect size, while avoidant attachment showed the same pattern of associations, although with a small effect size. As assessed with the ECR-M16, attachment avoidance and anxiety showed positive correlations with measures of depression (Lo et al., 2009), and with measures of depression, anxiety, and demoralization (Phillipp et al., 2017), particularly referring to attachment anxiety.

With respect to coping strategies, Schmidt et al. (2002) investigated a sample of patients with three kinds of disease (breast cancer, chronic leg ulcer, and androgenetic alopecia), using Adult Attachment Interview as a measure of adult attachment. They found that an insecure attachment seems to be related to less flexible coping. More specifically, from an observer perspective, an avoidant attachment style was associated with diverting coping strategies, while an ambivalent attachment style showed a stronger association with a negative emotional coping style. Conversely, the self-reported coping strategies of avoidantly attached persons were characterized by deactivating strategies, while the self-report of those with ambivalent attachment was characterized by hyperactivating tendencies. In the study by Cicero et al. (2009), patients with high levels of anxious attachment were characterized by lower fighting spirit, high levels of helplessness/hopelessness, and anxious preoccupation. The authors pointed out that the cognitive schema of patients with anxious attachment could be characterized by a sense of uncontrollability of the disease and of unavoidability of negative outcomes.

Holwerda et al. (2013) discriminated between secure and insecure attachment (evaluated with the Attachment Style Interview), finding that insecurely attached patients showed less trust in their physician compared to securely attached ones. Alternatively, Hinnen et al. (2014) showed that being able to discriminate between attachment anxi- ety and avoidance can be helpful since lower levels of trust were associated with reported emotional distress and physical limitations in more anxiously attached individuals but not in those less anxiously attached.

In light of these findings, and in line with other studies discussing the differences in illness behaviors showed by patients with respect to their attachment styles (e.g., Hunter \& Maunder, 2001; Tan, Zimmermann, \& Rodin, 2005), it is possible to acknowledge that the discrimination between anxious and avoidant attachment dimensions is a potentially useful clinical practice, oriented to better suit the patients' medical and psychological/psychopathological demands, particularly when they are experiencing painful conditions, such as cancer or other chronic diseases.

A few limitations of this preliminary study should be mentioned. First, the number of subjects and the overall design did not allow us to perform an EFA followed by a CFA. Second, no external measure of adult attachment was administered to assess construct validity (a limitation shared with the study by Lo et al. in 2009). Third, there is the issue of the positively keyed items of the ECR (Brennan et al., 1998; Lo et al., 2009; Phillipp et al., 2017), which are not balanced between the avoidance and anxiety scales, which is an issue that should be addressed on a broader scale in future studies.

\section{Conclusions}

From a clinical perspective, attachment theory offers a background to interpret differences in patients' adjustment pathways when facing medical diseases. Considering the attachment dimensions may help healthcare providers in building stronger therapeutic relationships, which in turn are expected to result in a better clinical alliance and improved compliance with oncological treatments (Hazan \& Shaver, 1994; Smith \& George, 2012; Tan et al., 2005). In this regard, we adapted the Brief Modified ECR to the Italian language to provide a feasible and easy-to-administer tool to evaluate attachment and to be used with inpatients and outpatients in the Italian medical context. As we discussed in the previous sections, considerable differences emerged on the level of the underlying factor structure and psychological dimensions assessed with this questionnaire, pushing us to call for further research on these topics. For example, to our knowledge, since the study by Lo et al. (2009), the ECR-M16 has been specifically administered to cancer patients. Future research should more clearly address how a non-clinical sample will respond to the ECRM16. It is likely that this will shed light on the psychological dimensions assessed by the modified ECR in different samples. Moreover, a comprehensive understanding of attachment styles in the broader context of multi-motivational dynamics (Cortina \& Liotti, 2014; Lichtenberg, 1989; Panksepp \& Biven, 2012) along with a more sophisticated knowledge of basic emotions (Celeghin, Diano, Bagnis, Viola, \& Tamietto, 2017), emotion regula- 
tion (Giromini, Velotti, de Campora, Bonalume, \& Zavattini, 2012; Gratz \& Roemer, 2004; Mikulincer \& Shaver, 2016), and assessment of empathy dynamics (Di Girolamo, Giromini, Winters, Serie, \& de Ruiter, 2017; Reniers, Corcoran, Drake, Shryane, \& Vollm, 2011), may deeply improve efficacy and efficiency of psychological interventions, providing a multifaceted framework to better understand patients' support needs. In this regard, further studies aimed at evaluating the ECR-M16 within this framework that address the development and evaluation of support interventions tailored to different attachment-style dimensions are extremely encouraged.

\section{References}

Bowlby, J. (1969/1982). Attachment and Loss. Vol. I: Attachment. New York: Basic Books.

Brennan, K. A., Clark, C. L., \& Shaver, P. R. (1998). Self-report measurement of adult attachment. In J. A. Simpson, \& W. $\mathrm{S}$. Rholes, Attachment theory and close relationships (pp. 46-76). New York: The Guildford Press.

Bretherton, I., \& Munholland, K. A. (2016). The internal working model construct in light of contemporary neuroimaging research. In J. Cassidy, \& P. R. Shaver, Handbook of Attachment. Theory, Research, and Clinical Applications (pp. 6388). Third Edition. New York: The Guildford Press.

Celeghin, A., Diano, M., Bagnis, A., Viola, M., \& Tamietto, M. (2017). Basic emotions in human neuroscience: neuroimaging and beyond. Frontiers in Psychology, 8.

Cicero, V., Lo Coco, G., Gullo, S., \& Lo Verso, G. (2009). The role of attachment dimensions and perceived social support in predicting adjustment to cancer. Psycho-Oncology, 18(10), 1045-1052.

Ciechanovski, P. S., Katon, W. J., Russo, J. E., \& Walker, E. A. (2001). The patient-provider relationship: attachment theory and adherence to treatment in diabetes. American Journal of Psychiatry, 158(1), 29-35.

Cortina, M., \& Liotti, G. (2014). An evolutionary outlook on motivation: implications for the clinical dialogue. Psychoanalytic Inquiry: A Topical Journal for Mental Professionals, 34(8), 864-899.

Crowell, J. A., Fraley, R. C., \& Roisman, G. I. (2016). Measurement of individual differences in adult attachment. In J. Cassidy, \& P. R. Shaver, Handbook of Attachment. Theory, Research, and Clinical Applications (pp. 598-635). New York: The Guildford Press.

Di Girolamo, M., Giromini, L., Winters, C. L., Serie, C. M., \& de Ruiter, C. (2017). The questionnaire of cognitive and affective empathy: a comparison between paper-and-pencil versus online formats in italian samples. Journal of Personality Assessment. doi:10.1080/00223891.2017.1389745

Fabrigar, L. R., Wegener, D. T., MacCallum, R. C., \& Strahan, E. J. (1999). Evaluating the use of exploratory factor analysis in psychological research. Psychological Methods, 4(3), 272-299.

Feeney, J. (2000). Implications of attachment style for patterns of health and illness. Child: Care, health and Development, 26(4), 277-288.

Feeney, J. A., \& Ryan, S. M. (1994). Attachment Style and affect regulation: relationships with health behavior and family ex- periences of illness in a student sample. Health Psychology, 13(4), 334-345.

Floyd, F. J., \& Widaman, K. F. (1995). Factor analysis in the development and refinement of clinical assessment instruments. Psychological Assessment, 7(3), 286-299.

Fortuna, K., \& Roisman, G. I. (2008). Insecurity, stress, and symptoms of psychopathology: contrasting results from selfreports versus interviews of adult attachment. Attachment \& Human Development, 10(1), 11-28.

Fraley, R. C., Hudson, N. W., Heffernan, M. E., \& Segal, N. (2015). Are adult attachment styles categorical or dimensional? a taxometric analysis of general and relationshipspecific attachment orientations. Journal of Personality and Social Psychology, 109(2), 354-368.

Giromini, L., Velotti, P., de Campora, G., Bonalume, L., \& Zavattini, G. C. (2012). Cultural adaptation of the difficulties in emotion regulation scale: Reliability and validity of an Italian version. Journal of Clinical Psychology, 68(9), 989-1007.

Gratz, K. L., \& Roemer, L. (2004). Multidimensional assessment of emotion regulation and dysregulation: development, factor structure, and initial validation of the difficulties in emotion regulation scale. Journal of Psychopathology and Behavioral Assessment, 26(1), 41-54.

Griffin, D., \& Bartholomew, K. (1994). Models of the Self and other: fundamental dimensions underlying measures of adult attachment. Journal of Personality and Social Psychology, 67(3), 430-445.

Harding, R., Beesley, H., Holcombe, C., Fisher, J., \& Salmon, P. (2015). Are patient-nurse relationships in breast cancer linked to adult attachment style? Journal of Advanced Nursing, 71(10), 2305-2314.

Hawkins, A. C., Howard, R. A., \& Oyebode, J. R. (2007). Stress and coping in hospice nursing staff. The impact of attachment styles. Psycho-Oncology, 16, 563-572.

Hazan, C., \& Shaver, P. (1987). Romantic love conceptualized as an attachment process. Journal of Personality and Social Psychology, 52(3), 511-524.

Hazan, C., \& Shaver, P. R. (1994). Attachment as an organizational framework for research on close relationships. Psychological Inquiry, 5(1), 1-22.

Hinnen, C., Pool, G., Holwerda, N., Sprangers, M., Sanderman, R., \& Hagedoorn, M. (2014). Lower levels of trust in one's physician is associated with more distress over time in more anxiously attached individuals with cancer. General Hospital Psychiatry, 36, 382-387.

Holwerda, N., Sanderman, R., Pool, G., Hinnen, C., Langendijk, J. A., Bemelman, W. A., ... Sprangers, M. A. (2013). Do patients trust their physician? The role of attachment style in the patient-physician relationship within one year after a cancer diagnosis. Acta Oncologica, 52(1), 110-117.

House, J. S., Landis, K. R., \& Umberson, D. (1988). Social relationships and health. Science, 241, 540-545.

Hunter, J. J., \& Maunder, R. G. (2001). Using attachment theory to understand illness behavior. General Hospital Psychiatry, 23, 177-182.

Kobak, R., Zajac, K., \& Madsen, S. D. (2016). Attachment disruptions, reparative processes, and psychopathology: theoretical and clinical implications. In J. Cassidy, \& P. R. Shaver, Handbook of Attachment. Theory, Research, and Clinical Applications. (pp. 25-39). Third Edition. New York: The Guildford Press.

Lichtenberg, J. D. (1989). Psychoanalysis and Motivation. Hillsdale: The Analytic Press. 
Lo, C., Hales, S., Jung, J., Chiu, A., Panday, T., Rydall, A., ... Rodin, G. (2014). Managing Cancer And Living Meaningfully (CALM): phase 2 trial of a brief individual psychotherapy for patients with advanced cancer. Palliative Medicine, 28(3), 234-242.

Lo, C., Walsh, A., Mikulincer, M., Gagliese, L., Zimmermann, C., \& Rodin, G. (2009). Measuring attachment security in patients with advanced cancer: psychometric properties of a modified and brief Experiences in Close Relationships scale. Psycho-Oncology, 18, 490-499.

Lorenzo-Seva, U., \& ten Berge, J. M. (2006). Tucker's congruence coefficient as a meaningful index of factor similarity. Methodology, 2, 57-64.

Maunder, R. G., \& Hunter, J. J. (2001). Attachment and psychosomatic medicine: developmental contributions to stress and disease. Psychosomatic Medicine, 63, 556-567.

Maunder, R. G., \& Hunter, J. J. (2016). Can patients be 'attached' to healthcare providers? An observational study to measure attachment phenomena in patient-provider relationships. BMJ Open, 6. doi:10.1136/bmjopen-2016-011068

McWilliams, L. A., \& Bailey, S. J. (2010). Associations between adult attachment ratings and health conditions: evidence from the national comorbidity survey replication. Health Psychology, 29(4), 446-453.

Mikulincer, M., \& Shaver, P. R. (2016). Adult attachment and emotion regulation. In J. Cassidy, \& P. R. Shaver, Handbook of Attachment. Theory, Research, and Clinical Applications (pp. 507-533). Third Edition. New York: The Guildford Press.

Nicholls, W., Hulbert-Williams, N., \& Bramwell, R. (2014). The role of relationship attachment in psychological adjustment to cancer in patients and caregivers: a systematic review of the literature. Psycho-oncology, 23(10), 1083-195.

Nissen, K. G. (2016). Correlates of self-rated attachment in patients with cancer and their caregivers: a systematic review and meta-analysis. Psycho-Oncology, 25, 1017-1027.

O'Connor, B. (2000). SPSS and SAS programs for determining the number of components using parallel analysis and Velicer's MAP test. Behavior Research Methods, Instruments, \& Computers, 32(3), 396-402.

Panksepp, J., \& Biven, L. (2012). The Archaeology of Mind. New York: Norton and Company.

Phillipp, R., Vehling, S., Scheffold, K., Grunke, B., Harter, M., Mehnert, A., ... Lo, C. (2017). Attachment insecurity in advanced cancer patients: psychometric properties of the German version of the Brief Experiences in Close Relationships Scale (ECR-M16-G). Journal of Pain and Symptom Management, 54(4), 555-562.

Picardi, A., Vermigli, P., Toni, A., D’Amico, R., Bitetti, D., \& Pasquini, P. (2002). Il questionario "Experiences in Close Relationships" (ECR) per la valutazione dell'attaccamento negli adulti: ampliamento delle evidenze di validità per la versione italiana. Journal of Psychopathology, 3. Available from: http://www.jpsychopathol.it/article/il-questionario-experiences-in-close-relationships-ecr-per-la-valutazione-dellattaccamento-negli-adulti-ampliamento-delle-evidenze-di-v alidita-per-la-versione-italiana/

Pietromonaco, P. R., Uchino, B., \& Schetter, C. D. (2013). Close relationship processes and health: implications of attachment theory for health and disease. Health Psychology, 32(5), 499-513.

Reniers, R. L., Corcoran, R., Drake, R., Shryane, N. M., \& Vollm, B. A. (2011). The QCAE: A questionnaire of cognitive and affective empathy. Journal of Personality Assessment, 93(1), 84-95.

Scharfe, E., \& Eldredge, D. (2001). Associations between attachment representations and health behaviors in late adolescence. Journal of Health Psychology, 6(3), 295-307.

Schmidt, S. D., Blank, T. O., Bellizzi, K. M., \& Park, C. L. (2012). The relationship of coping strategies, social support, and attachment style with posttraumatic growth in cancer survivors. Journal of Health Psychology, 17(7), 1033-1040.

Schmidt, S., Nachtigall, C., Wuethrich-Martone, O., \& Strauss, B. (2002). Attachment and coping with chronic disease. Journal of Psychosomatic Research, 53, 763-773.

Shaver, P. R., \& Mikulincer, M. (2002). Attachment-related psychodynamics. Attachment \& Human Development, 4(2), 133-161.

Smith, J. D., \& George, C. (2012). Therapeutic assessment case study: treatment of a woman diagnosed with metastatic cancer and attachment trauma. Journal of Personality Assessment, 94(4), 331-344.

Tan, A., Zimmermann, C., \& Rodin, G. (2005). Interpersonal processes in palliative care: an attachment perspective on the patient-clinician relationship. Palliative Medicine, 19, 143-150.

Tsilika, E., Parpa, E., Galanopoulou, N., Gennimata, V., Mosa, E., Galanos, A., \& Mystakidou, K. (2016). Attachment orientations of Greek cancer patients in palliative care. A validation study of the Experiences in Close Relationships scale (ECR-M16). JBUON, 21(4), 1005-1012.

Tuck, N. L., \& Consedine, N. S. (2015). Breast cancer screening: The role of attachment. Psychology, Health \& Medicine, 20(4), 400-409.

Turner-Cobb, J. M., Gore-Felton, C., Marouf, F., Koopman, C., Kim, P., Israelski, D., \& Spiegel, D. (2002). Coping, Social support, and attachment style as psychosocial correlates of adjustment in men and women with HIV/AIDS. Journal of Behavioral Medicine, 25(4), 337-353.

World Medical Association. (2013). World Medical Association Declaration of Helsinki: Ethical Principles for Medical Research Involving Human Subjects. Journal of American Medical Association, 310(20), 2191. 